\title{
Sujetos colectivos y procesos de trabajo interrogados en triálogo coproductivo. Acerca de la producción social de conocimiento
}

\author{
Alberto L. Bialakowsky ${ }^{1}$, Cecilia Lusnich, Delia \\ Elena Franco, José Manuel Grima², Omar Navarro, \\ Elsa Calvo, Pedro Santillán, Nora Bardi ${ }^{3}$, Antonio \\ Panszcyk, Jorge Thierbach, Oscar Campilongo ${ }^{4}$ y \\ Alomai Rodríguez ${ }^{5}$
}

\begin{abstract}
Resumen
El énfasis de los aspectos conceptuales y epistemológicos planteados aquí, invita a elaborar y profundizar una mirada compleja como posibilidad para de-velar y des-ficcionalizar procesos, como así sus efectos sociales y subjetivos, promoviendo como punto de partida una interrogación colectiva, no transferida. Sus productos y sus efectos se reflejan en una resignificación que condensa la valoración de su producción cognoscitiva investigativa y el instrumento convergente en su resistencia. Paralelamente, nos dirigimos a revisar desde una perspectiva crítica la producción usual del saber y la relación social entre investigadorinvestigado y el lugar de la ciencia como afluente del cambio.
\end{abstract}

Palabras clave: producción de conocimiento; sujetos colectivos; coproducción investigativa.

\begin{abstract}
The emphasis of the conceptual and epistemological issues raised here invite you to develop a deeper and more complex viewpoint as a possibility to bring to light and break the myths around processes, as well
\end{abstract}

1 Sociólogo, Director del Proyecto de investigación UBACyT S064 "Poblaciones extinguibles en nueva época. Análisis de Procesos de Trabajo Institucionales y Sujetos Colectivos en intersección con una praxis transdisciplinaria", Instituto de Investigaciones Gino Germani, Facultad de Ciencias Sociales, Universidad de Buenos Aires (UBA). E-mail: albiala@gmail.com

2 Sociólogos, investigadores del Proyecto de Investigación UBACyT S064.

3 Enfermeros del Hospital J. T. Borda, Buenos Aires y maestra de Provincia de Buenos Aires, coproductores del Proyecto de Investigación UBACyT S064.

4 Federación Gráfica Bonaerense, coproductores del Proyecto de Investigación UBACyT S064.

5 Estudiante avanzada de la Carrera Sociología, Facultad de Ciencias Sociales, UBA. 
Sujetos colectivos y procesos de trabajo interrogados en triálogo coproductivo

as their social and subjective effects, promoting a collective question as a starting point, not transferred. Their products and effects are reflected on a new meaning that condenses the assessment of their cognitive research production and the converged instrument in their resistance. In parallel, a review of the usual production of knowledge and the social relationship between researcher and the product researched from a critical point of view and the place of science as a means of change has been addressed.

Key words: knowledge production; collective subjects, co-research production. 


\section{Nota inicial}

Las empresas recuperadas ${ }^{6}$ y la institución estatal de salud constituyen una oportunidad de interrogación múltiple y recursiva acerca del producir y del investigar en nueva época, como así la elaboración teórica a través del "triálogo" desarrollado entre investigadores, coproductores y protagonistas laborales acerca de los procesos de trabajo y la producción de conocimiento.

La experiencia investigativa compartida, desde nuestra perspectiva, implica construir una mirada compleja, al menos en tres niveles de análisis: a. un nivel macro social, en el que se tensan y distienden dialécticamente los vínculos entre las políticas públicas (educativas, laborales y salud) y los actores sociolaborales; b. un nivel meso social, en el que se reproducen los procesos sociales de trabajo institucionales, y, c. el espacio micro social, en el que se modulan subjetividades mortificadas al mismo tiempo que resistentes individual y colectivamente.

El énfasis de los aspectos conceptuales y epistemológicos planteados aquí, invitan a elaborar y profundizar una mirada

6 Las experiencias laborales autogestionarias tienen, en Argentina, una vasta y feraz historia desde comienzos del siglo XX. No obstante, el fenómeno de recuperación de empresas por parte de sus trabajadores cobró singularidad y caracteres de especificidad a finales de la década de los 90 e inicios del siglo XXI, en un contexto de profunda crisis, en el cual el desempleo, el subempleo, la pobreza y la indigencia alcanzaban sus más altos niveles "históricos" (Rebón y Salgado, 2007; Candia, 2006). Contexto éste en que el mercado laboral padecía tres impactos simultáneos: 1. destrucción record del nivel de empleo por profundización del cuadro recesivo; 2 . mantenimiento de procesos de reducción nominal de salarios tanto por disposiciones institucionales como por la capacidad de profundizar la sobreexplotación laboral con extensión del desempleo y la precariedad; 3. caída del salario real y, por lo tanto, del poder adquisitivo. Con el proceso de restablecimiento económico registrado a partir del 2003, las empresas recuperadas por sus trabajadores siguen en pie e incluso se han incrementado. Aun cuando la rentabilidad generada por estos establecimientos en muchos casos es menor que el promedio de la rama en la cual se insertan, y a pesar que el "retiro", ingreso sustituto del salario, que extraen los trabajadores en las fábricas recuperadas (cooperativizadas) resulta en frecuentes oportunidades menor a sus necesidades, estos colectivos recuperadores resisten y continúan luchando por sustentarse. Se estima que en el país, durante el año 2010, funcionaban 205 empresas recuperadas, cuya fuerza laboral en conjunto ocupaba a un total de 9.362 trabajadores. En comparación con el año 2004, puede observarse que el fenómeno no se ha detenido sino que se sostiene, ya que en aquella fecha se estimaba la existencia de 161 empresas recuperadas con un total de 6.900 trabajadores (Salgado, 2010). 
compleja como posibilidad para de-velar y des-ficcionalizar procesos, como así sus efectos sociales y subjetivos, promoviendo como punto de partida una interrogación colectiva, no transferida. Sus productos y sus efectos se reflejan en una resignificación que condensa la valoración de su producción cognoscitiva investigativa y el instrumento convergente en su resistencia. Paralelamente, se dirige a revisar desde una perspectiva crítica la producción usual del saber, la relación social entre investigador-investigado y el lugar de la ciencia como afluente del cambio.

\section{Acerca del ensayo del encuentro discursivo y el pensamiento múltiple}

La producción histórica de conocimiento se ha visto atravesada por procesos de apropiación y negación del saber del otro, enmarcados en la ficcionalización del montaje del conocimiento "para" y "por" el otro, incluso en la invención del otro. Ficción que las corrientes del pensamiento como el iluminismo, positivismo, evolucionismo y eurocentrismo han acentuado en las ciencias sociales y en la sociología (Quijano, 2000).

El proceso de concentración y apropiación científico-tecnológica constituye, en la producción de conocimiento, un punto nodal para comprender el vínculo normal que se establece entre un sujeto que conoce activamente y un objeto pasivo o pasible de ser conocido. En este modelo la capacidad autónoma de conocer -y de apropiarse de ese conocimiento- sólo corresponde al sujeto investigador.

Es así que el diseño positivista como forma de dominación cultural y el objetivismo como instrumento de control, tienen su correlato en la visión antidialéctica y unidimensional de la realidad, especializada y fragmentaria (Giroux, 2003).

El reduccionismo, la unidimensionalidad (Marcuse, 1968) y la unidireccionalidad (Sotolongo Codina y Delgado Díaz, 2006) han fortalecido dicha práctica de producción de conocimientos, que no reconoce la alteridad ni la validez científica del aporte de 
esa alteridad. La exclusión epistemológica que se instala con esta práctica significa una forma de "epistemicidio" (De Sousa Santos, 2006), el exterminio del saber del otro diferente.

En este ensayo, entonces, considerar como eje central la noción de sujetos colectivos laborales reivindicativos como sujetos coproductores de conocimiento, implica, también, interrogarse por los procesos de fragmentación y descolectivización que acontece en la producción de conocimiento en el contexto capitalista actual.

En las últimas décadas se experimentaron grandes cambios; las grandes empresas y ciudadelas de contorno obreras han sido sustituidas por numerosos satélites fabriles, capaces de replegar incluso el trabajo hacia el domicilio, alcanzando con ello nuevas formas asociativas, produciendo efectos de desagregación y fragmentación material dentro de la masa industrial.

La regulación regida por los contratos de larga duración, el contrato fijo, que sostenía el sentido de previsibilidad, ha sido sustituida por la subcontratación, el trabajo eventual, formas que precarizan y fragilizan la identidad colectiva, limitando su capacidad para forjar vínculos de largo plazo.

Estos procesos, se observa, van dando lugar a la emergencia de "identidades contingentes" con el establecimiento de una dinámica que produce "contornos difusos", entre el espacio del trabajo y del no trabajo (Bhabha, 1993, 1997; Beck, 2000, García Linera, 2001).

En este marco, la nueva regulación, en sustitución del modo antecedente taylorista-fordista, adoptó formas drásticas, pragmáticas y coyunturales que tendieron a legitimarse y legalizarse en el largo plazo, no sólo en el campo económico y laboral sino también en lo social y cultural. Desde el concepto de biocapital (Osorio, 2006) el vínculo capital-corporeidad del trabajador pone en evidencia los cimientos de un orden social que reposa en el poder del capital sobre la vida misma, rige un antagonismo y complementariedad entre el capital y el trabajo, entre el capital y vida. En términos del 
análisis vale diferenciarlas, a la vez que integrarlas. La separación forma parte de los velos que ocultan el vínculo mortífero.

Los procesos de trabajo tanto fabriles como los institucionales estatales, operan intersubjetivamente velando la posibilidad de comprender esta mortificación, especialmente, cuando el padecimiento no suscita un movimiento colectivo de resistencia. Incluso, el difuminado de las huellas de la opresión no solamente conllevan silencio y simulación, sino también mecanismos mortíferos del "borrar la memoria" (Dejours, 2006).

La lógica metódica del contexto intenta modelar así subjetividades des-colectivizadas. En paralelo a estos mismo procesos, el saber acerca de la lucha, obra (Vasilachis, 2001) resistencia, en tanto devela las sustracción del capitalismo cuando intenta poner en práctica una de las distintas formas de conversión del patrimonio común. En donde el saber cómo luchar, en tanto mercancía real, se vacía de contenido por los mecanismos de apropiación en los procesos sociales de trabajo, y es transformado en mercancía ficticia $^{8}$ (Polanyi, 2001). Así, el obrar resistencia, obra descubrimiento, en donde la dominación no es ni absoluta ni total:

“...la lucha hoy compañera no es solo por la recuperación del trabajo, de los puestos de trabajo o de los medios de producción, sino por otra calidad de vida. Una lucha que nos una a todos los trabajadores independientemente del lugar que se ocupa" (Trabajador grafico, 2009)

7 "Al mencionado riesgo del imperialismo de los códigos y de los conceptos críticos se suma la presuposición de que sólo algunos sujetos tienen el "saber" legitimado para generar representaciones discursivas, no específicamente sobre su propio trabajo sino sobre el trabajo de otros. Ese peligro radica en la implícita aceptación de una forma de diferenciación social basada no ya sobre la posesión de bienes materiales sino simbólicos. Este consentimiento llevaría a desconocer la capacidad de todo hombre y mujer y de todos los hombres y mujeres de reflexionar sobre su actividad y sobre el sentido de ésta en relación con su identidad y con la posibilidad de modificar el orden de relaciones sociales que impide o menoscaba el despliegue de esa identidad. Es en la admisión de esa capacidad en la que basaré mi reflexión sobre la obra y su diferencia con el trabajo" (Vasilachis, 2001: 5).

8 Karl Polanyi distingue entre mercancías reales y ficticias; las primeras son aquellas creadas para circular en el mercado; las segundas, como el trabajo, la tierra y el dinero, no fueron producidas para tal efecto (Polanyi, 2001). 


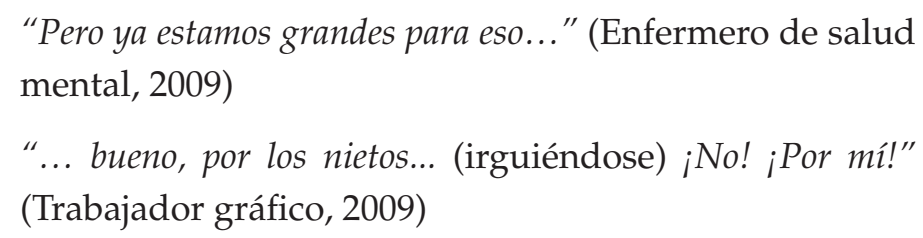

La noción de sujeto colectivo resistente como productor de saber implica, en nuestra experiencia investigativa, la renovación de las interrogaciones en sus diversos niveles de contenido como la propia revisión de práctica investigativa.

"En el trabajador aislado, la fragmentación sería como saberes desparramados. Y la desfragmentación (tomado de la informática) actuaría reordenando ese saber y resignificándolo. La desfragmentación es parte del dispositivo. La idea de cambio institucional, en lo personal me produjo un desafío tremendo... cuando Delia pregunta: ¿usted dice entonces que se perdió la solidaridad entre los compañeros?, yo pregunto: ¿cuándo se perdió? Decirlo es fácil como lugar común. Pero a la hora de recordarlo, enmarcarlo, diagnosticarlo, hay que buscarlo en uno mismo, y también en los personajes que estuvieron formando parte de ese proceso. Yo tomé y volqué lo que había en mi...lo escribí... Cuando lo estaba por presentar un montón de ideas comenzaron a surgir, lo que me obligó a reescribirlo sobre la hora... El cambio fue un reordenamiento y aclarar algunos conceptos... Una vez presentado en "encuentros de enfermeros" me pareció que había que seguir dándole otras vueltas más... El dispo (dispositivo de coproducción investigativa) interactúa produciendo más preguntas y más saberes." (Coproductor, enfermero en salud mental, 2009)

Coproducir mediante un dispositivo de co-investigación implica la tarea común de la construcción de: a. un marco teórico de referencia, a la vez que flexible, provisorio y acumulativo; $b$. una metodología, y c. la transformación subjetiva, en tanto los participantes interrogadores devienen en productores de diálogo y reciprocidad en la transversalidad metódica. 
Así, el reconocimiento entre productores (Dejours et al, 1998), puede resultar un síntoma promisorio de ruptura con el trabajo alienado. Se hace visible en este ensayo que, el encuentro discursivo y el pensamiento múltiple que se despliega en el diálogo, dispara y reconstruye conceptos sostenidos por la materialidad del colectivo.

La resistencia del contramétodo al método usual descolectivizante, develaría sus contradicciones, desficcionalizando su duplicidad social:

“... viví al estudiante que se recibía y que era al revés de la Universidad y cuando tenía que cumplir un rol en una fábrica o en un taller determinado... psicólogo, ingeniero... estaban al servicio de las patronales y de la opresión y no veían con claridad lo que los trabajadores planteábamos en un momento determinado" (Trabajador gráfico, 2009).

"La palabra manicomio me sigue rondando, el loquero... están escindidos del afuera, ¿cuál es la línea divisoria, el límite? No ven a los hombres, a las mujeres, a los niños, como un producto de la sociedad, que estallan... Nosotros (los "sanos") somos los sobrevivientes del sistema... Si no hubiésemos resistido estaríamos adentro. Las condiciones sociales de vida capitalista son las generadoras de enfermedad social" (Trabajador gráfico, 2009)

De ahí que lo cotidiano, el mundo de la intersubjetividad, constituya una dimensión espacio-temporal en que la vivencia de los excesos de regulación se manifiestan, así como las opresiones concretas en que estos se desdoblan. Una vez liberada, puesta en descubrimiento, la ficción capitalista, que reflejan condiciones de vida pasadas y que son, por lo tanto, conservadoras, estratos fosilizados para Gramsci (2000) y que convergen a reproducir las relaciones sociales de producción. La tarea de descubrir las opresiones y de la lucha contra ellas, constituye potencialmente una tarea $\sin$ fin, sin un sujeto social específicamente determinado (De Sousa Santos, 2001) pero capaz de aunar develamiento y praxis, resistencia social y cognoscitiva. 
Es posible comprender entonces el ensayo del pasaje de la cooperación despótica (Marx, 1867) a la cooperación participativa-solidaria, podría replantear un sujeto coproductor de conocimiento colectivo e individual, que lleva el interrogante al núcleo de las formas de producción, distribución y apropiación del conocimiento, dimensiones indisociables y simultáneas, en el que una no puede darse sin la otra, a diferencia de la lógica metódica tradicional, que niega la subjetividad colectiva (Osorio, 2006).

\section{Lo productivo y el sujeto colectivo de conocimiento desde la praxis de la coproducción investigativa}

Los procesos de producción de conocimiento, especialmente en ciencias sociales, operan en relación con colectivos productivos y, sobre esta base, se sostiene un tipo determinado de producción, tal como lo venimos analizando, estableciéndose una relación subordinada, silenciada metodológicamente.

Nuestro intento busca irrumpir en la relación-escisión histórica entre el "sujeto" y el "objeto", por medio del instrumento metodológico de la coproducción investigativa: la interrogación coproducida, los sujetos colectivos de cambio, los dispositivos cognoscitivos de larga duración y la recuperación reflexiva en el propio proceso de la recuperación productiva.

Las empresas recuperadas y las instituciones estatales de salud, aunque áreas aparentemente dispares, constituyen una oportunidad de interrogación múltiple y recursiva acerca de producir e investigar, al constituirse-instituirse como campo de acción reflexiva y producción de dispositivos cognoscitivos. La praxis coproductiva intenta superar el hiato impuesto por los procesos de trabajo y las metodologías descolectivizantes (en sentido de su materialidad productiva), entre el hacer y el pensar, entre el sujeto singular y el sujeto colectivo, entre lo productivo y lo reflexivo.

La metodología de coproducción investigativa (Bialakowsky, et al., 2009) reconoce entre sus supuestos e hipótesis: a. que los 
conocimientos son producidos socialmente y que se observa en la asimetría entre investigador-investigado como obstáculo para la producción de conocimiento y la resolución de los problemas que la ciencia social enfrenta; $b$. que el pensamiento individual es complementario del pensamiento colectivo y recíprocamente, c. que resulta necesario desarrollar dispositivos de coproducción investigativa en otros espacios institucionales y comunitarios exouniversitarios, con el fin de investigar asociadamente con actores coproductores, promoviendo el co-descubrimiento y el encuentro discursivo; d. el abordaje transdisciplinario de las problemáticas sociales a partir del marco del paradigma de la complejidad, entre disciplinas y más allá de las disciplinas (Morin, 1994).

En esta propuesta, la simetría intersubjetiva y la transdisciplinariedad se postulan como instrumentos para el cambio en las prácticas productivas de conocimiento y remiten, a su vez, a una revisión material de su proceso social de trabajo (Bialakowsky, et al., 2009).

Operativamente la coproducción investigativa se desarrolla en el campo y, al mismo tiempo, en el propio espacio universitario, promoviendo inicialmente acuerdos interinstitucionales a partir del diálogo entre los actores, el descubrimiento de demandas y su mutuo reconocimiento como instancia motivadora para la investigación, dirigida en un espacio de encuentro de saberes a la interrogación en común:

“...en un momento determinado había como un quiebre en los estudiantes que se recibian, todos se habian recibido en su rebeldía en la Universidad y después lo volcaban todo en sentido contrario... (Hoy) me causa una gran satisfacción en lo personal, que ustedes estudien la problemática de la clase trabajadora para cambiar y para cambiar la sociedad... es fundamental porque la sociedad necesita la temática y la orientación científica... el conocimiento. Tiene que haber un criterio sólido en la unidad entre la producción y la orientación universitaria. No puede haber producción, a mi criterio, en el mundo que se 
viene, si no interviene la Universidad." (Trabajador gráfico, 2009).

En esta experiencia vista como cadena productiva, se codescubren las muralidades simbólicas que instalan tensión entre los trabajadores y los coproductores, entre cursantes y docentes, entre trabajadores e investigadores. El método coproductivo contempla, de este modo, la potencialidad recursiva incorporando al proceso de descubrimiento posibilidades de reflexividad sobre los procesos sociales que se abordan, diluyendo -al menos en parte- la violencia simbólica propia de la asimetría que se ejerce en los procesos de investigación (Bourdieu, 1993).

“...me llevó a recordar cómo en cuatrimestres previos se llegó a plantear que el sociólogo/a debía "bajar" el nivel, en el sentido de que ese otro con quienes nos vinculamos tiene un nivel "inferior". Acá sin duda hay que intervenir con reflexiones que posibiliten develar los procesos de reificación de orden epistemológico-conceptual-metodológicos" (Investigadora docente, 2009).

"Se me ocurren un par de cosas, no sé si es en esa dirección. Cuando se habla de "bajar el nivel del lenguaje" para su comprensión, me parece que se está hablando del lenguaje, como parte constitutiva de un discurso dominante, sobre otro subordinado, creo que mencionar esos desniveles de lenguaje, está haciendo referencia a relaciones de poder asimétricas, donde la incomprensión tendría doble dirección, o efecto." (Coproductora, enfermera en salud mental, 2009)

\section{Triálogo. Solidaridad conceptual, solidaridad subjetiva}

\section{¿Cómo se compone entonces el triálogo?}

Reflexionando acerca de la práctica compartida: "...no podía creer que estos espacios de discusión y conocimiento transcurrieran en el Borda, que hayamos podido concretar un encuentro de diferentes sectores, 
en un ámbito de respeto, se sentía la intención de todas y todos de que así fuera, de diálogo genuino. Muy contenta, honrada y gratificada de que se haya convocado desde el dispositivo de enfermeros, nada menos que a los cursantes - pensaba en ellos, fuera de los claustros acostumbrados-, a los gráficos... un esfuerzo de todos, compartiendo espacios poco conocidos para algunos, pero atravesados por problemáticas muy similares. Siempre es necesario y nunca suficiente mencionar que compartir lugares de cuidado, de buen trato y buenas intenciones derriba barreras inimaginables, tiende puentes para unir, para encontrar a alguien del otro lado (Coproductora enfermera de salud mental, 2009).

"Sobre la reunión del jueves 28-5-09 tomé algunos puntos medios dispersos (se nota que trabajo en el Borda), ante la consigna de: ¿se niega el sufrimiento en el trabajo?: Blanco, representante gremial de ATE, refiere: "la primera degradación es el salario, las Instituciones en Salud Mental son denostadas".

Pensaba que aceptar trabajar de esta forma también es degradación. "Acá hay 5 gremios, por eso se hizo una Multisectorial en donde resignamos cosas para estar juntos". Pensaba: que en vez de resignar, si no se podría aportar y pensar en común como Trabajadores para realmente estar juntos y romper con la fragmentación. Otro punto que apareció en reiteradas oportunidades, en Gráficos Oscar dijo: "Hay que organizarse colectivamente", "yo soy el otro". Jorge, hoy enfermero, planteó refiriéndose a su trabajo 15 años atrás, como gráfico, "a veces el Trabajador está agobiado, tiene desgano, está alienado por estar todo el tiempo en no sé qué máquina de la imprenta, trabajando automáticamente, solo, me sentía un vegetal". ¿No es la fragmentación un mandato institucional que impacta de distintas formas según los efectores? Entonces se descubrió el hilo conductor (para mí) que nos cruza a todos los Trabajadores cualquiera sea la actividad. No sé si me causó pesar, porque descubriendo el enemigo sé con quién voy a pelear, no, naturalizando el padecer. Por último, cuando nos vamos del Hospital, Delia me pregunta cómo estaba, le dije muy cansado, fue un día muy largo, el Borda me tiene muy cansado. Y me pregunta: “ ¿Esto también?... ¿Este encuentro también es en el Borda?". Le respondí: "No, esto me reconforta, el pensar y descubrir 
juntos todos con los Trabajadores de la UBA, inteligentes y sensibles cursantes, compañeros gráficos y del Hospital. Me sentí gratificado." (Registro etnográfico de coproductor enfermero de salud mental, 2009).

"Creo que la metáfora que siempre ensayamos es el encuentro entre dos lenguajes, sin traductor, sino que los actores en la escena coproductiva deben transformarse en lectores y traductores en doble dirección, o en tridirección. El triálogo es el mejor camino, en éste se visualiza una forma de puente. El resultado será un interlenguaje, o cuarto lenguaje creado por la coproducción, una, en su formato comunicativo investigativo, y otra, en la creación de nuevas palabras, conceptos, enlace teórico, puentes transdisciplinarios, entre trabajo y pensamiento, entre arte y ciencia, entre metáforas y ciencia" (Investigador docente, 2009).

"Cuando se menciona el encuentro de "dos lenguajes", luego un tercero y más tarde la conformación de un cuarto, se me hace difícil comprenderlo en esos términos, creo que los lenguajes están constituidos por todos los lenguajes, entrelazados, atravesados, superpuestos, de manera imperceptible para el que lo habla" (Coproductora, enfermera en salud mental, 2009).

"De eso trata la complejidad de la producción colectiva: intentar develar las lógicas en los procesos sociales de apropiación de ese plus, de creación interpretativa en la comunicación, que en su naturalización deviene dominio" (Investigadora docente, 2009).

"El lenguaje coproductivo tiene como fundamento el respeto. La comunicación se va profundizando y el intercambio de saberes produce conocimiento colectivo... La pedagogía tradicional establece niveles de portadores de conocimiento (Investigador docente, 2009).

El maestro posee el saber y lo imparte. El alumno (sin luz) recibe y se ilumina con ese saber dado, aunque no tenga nada que ver con su realidad, que no es tenida en cuenta. Por lo que el enriquecimiento mutuo no existe. Se me ocurre que la pedagogía co-productiva subsanaría los "como si" de la educación. Sería posible, así, la traspolación de las situaciones de aprendizaje, dando herramientas reales para la vida que 
permitirian humanizar, subjetivar, liberar, investigar, interrogar, y hacer posible un cambio individual y colectivo" (Coproductora, trabajadora en educación).

"¿Qué los llevó a la tarea de juntarse con gente de la Universidad?" (Cursante, 2009).

“...siempre me interesó el conocimiento, aprender y generar conciencia... y lo que me atrae de trabajar con la Universidad es la posibilidad de contactarse con la juventud... lo que queremos es que la Universidad no sea una fábrica de capataces." (Trabajador gráfico, 2009).

“...mostrar que hay otro sindicalismo y transmitir toda la experiencia que tenemos para que sea útil." (Trabajador gráfico, 2009).

El núcleo de esta metodología dialógica consiste en materializar a través del encuentro discursivo la potencia que guarda el colectivo como dispositivo cognoscitivo. A su vez esta praxis, al mismo tiempo que investiga y distribuye derecho de conocer, crea una relación triádica en el investigar. La terceridad del coproductor investigador introduce interrogantes desde otro lugar, si el diálogo es un instrumento básico de la investigación acción participativa (Fals Borda, 1987), el triálogo se constituye en una reapropiación del coproductor en su capacidad de investigar, con interrogaciones que le son propias aplicadas a otro campo, puestas en juego (y debate) de verdad, en análisis comparativo.

Así se introduce una terceridad en la interacción entre dos espacios academia-campo (sujetos diádicos), la interacción investigativa del triálogo que se establece entre investigadores y coproductores múltiples mutuamente interceptados.

En consecuencia, la solidaridad conceptual y la solidaridad subjetiva en el desarrollo teórico del con-junto compartido, en tanto, disolverían la violencia simbólica, muestra mostrándonos que este camino y esta forma son coproductivos. La praxis coproductiva abarca así, la forma discursiva de concebir y operar en todos los encuentros, por ello, la solidaridad conceptual y producir colectivos es una y la misma cosa. 


\section{Materialidad espacial y materialidad temporal}

Si antes la espacialidad resultaba simbólica en el sentido cartesiano, "pienso luego existo", la intersección entre investigadores y trabajadores coproductores deviene diálogo materializado en el encuentro.

En esta concepción el dispositivo, término frecuentemente utilizado por Foucault (1978), se le ha dado una especificidad, se trata del diseño de una herramienta social, colectiva, un instrumento cuya dinámica tiende a fortalecer y liberar la producción de conocimiento. El dispositivo implica la creación de un sujeto colectivo de conocimiento que en el marco de la propuesta metodológica contiene varias materialidades: temporales, espaciales, transversales.

Respecto de la materialidad temporal. Usualmente los dispositivos participativos de investigación agudizan lo presencial coyuntural, esta perspectiva se orienta a desarrollar la implicación investigativa en el largo plazo ${ }^{9}$, como instrumento idóneo de conocimiento y como derecho universal sustantivo. La temporalidad y universalidad colocan al dispositivo en una recursividad investigativa al mismo tiempo que una recursividad ética, en este sentido también identitaria.

Respecto de la materialidad espacial. La circulación, el movimiento y la corporeidad implican una opción de rediseñar los espacios con otro, sobre todo, saber "nos" que ese saber depende del otro (Lévinas, 1997; Morin, 1984), depende en este caso de la producción conjunta con el otro. Por ello, campo social, campo científico, campo educativo, se redefinen en el encuentro materialmente móvil y extendido extra-muralmente, donde el "para" científico es sustituido por el "con" y por el "co". Así, la transversalidad significa también una praxis común en todos los campos.

9 El desarrollo sostenido del equipo (2001-2011) de esta metodología de coproducción investigativa habilita a este reconocimiento temporal en praxis de indagación e interrogación conjunta con coproductores en puesta de encuentro de saberes. 
En el campo universitario esa otra pedagogía (de raíces freireanas), descubre la negación del estudiante como productor, e intenta trocar el alumno en cursante, y el cursante en coproductor de conocimiento.

Sobre el "juego de verdad" en campos intersectados:

“Desde mi participación en el taller pude ver que todos los saberes que nos son expropiados pueden ser retomados a partir de esta forma co productiva de pensar y de generar conocimiento. El taller ${ }^{10}$ propone una forma de trabajo colectivo de descubrimiento en donde el espacio discursivo toma vital importancia por lo que los participantes ponen en juego sus representaciones y apropiaciones mutuas intentando producir un espacio positivo en donde todas las voces son escuchadas" (Cursante en taller coproductivo, 2009).

"En la primera jornada, como hicimos tanta charla los chicos no pudieron exponer su pensamiento... Yo me acuerdo dos o tres de los chicos que hablaban, uno dijo que venía a cubrir las horas y después se fue con otra idea. Me parece que es interesante eso, ir con algo y después te levantas con otra cosa. Para mí es importante, que sepa que hay otras cosas, no es que terminó ahí y que no hay más nada que hacer." (Trabajador gráfico, 2009).

"Son cincuenta años, soy parte de este gremio, mi vida transcurrió acá... y todo lo que aprendí me gusta volcarlo a las nuevas generaciones porque no todas fueron rosas, también hubo muchas espinas..." (Trabajador gráfico, 2009).

"En diferentes informes he venido sosteniendo que en el taller trabajamos con un contra método, pero me parece más acertado aplicar la subversión, ya que no estamos contra nadie, sí defendemos el derecho universal de que todos participen de las ciencias sociales, acá tenemos otra versión y no la del paradigma positivista..." (Cursante en taller coproductivo, 2009).

10 Refiere a Taller anual de investigación: Extinción social, nuevos padecimientos y procesos sociales de trabajo, Carrera de Sociología, Facultad de Ciencias Sociales, Universidad de Buenos Aires. 
"Nora (coproductora enfermera) trae a la mesa algo que se han estado preguntando con Omar (coproductor enfermero): “Seríamos los mismos trabajadores que hoy somos si no se nos hubiera presentado la experiencia del taller?". Se responde a sí misma que seguramente no, asegura que la coproducción impacta en su trabajo y con su relación con aquellos que comparten espacio de trabajo con ella pero que no participan del dispositivo, dice: "No somos las mismas personas ni los mismos trabajadores". Omar opina también: "nos conmovimos al ver cómo nosotros mismos trabajábamos" (Registro del dispositivo de coproducción investigativo en salud mental, 2009).

\section{A modo de conclusiones}

El desafío de una ciencia social latinoamericana crítica (De Sousa Santos, 2001; Quijano, 2000; Dos Santos, 1998, Bhabha, 1993), consiste en repensar de nuevo los caminos de la síntesis y apertura, tomando como método, por un lado, la citación de lo acumulado en la experiencia histórica en la contemporaneidad, por negativa que haya resultado en el proceso de dominación, y por el otro, la disposición para identificar lo que se renueva en el tiempo presente y hace de él verdaderamente nuestro tiempo.

“... hoy fue un día terrible. Una nena de 1er grado, vino con la mano derecha lastimada. No se notaba a simple vista qué tipo de lesión tenía, pero se quejaba de dolor. Se había quemado en su casa, hacía varios días y no había recibido cuidados médicos ni curaciones y su pequeña mano despedía olor (a podrido). La maestra le avisa al equipo y el equipo va al domicilio a buscar a algún familiar. Esta niña había inasistido por alrededor de 10 días. Tiene una hermanita de 6 años y un hermano de 2 años, estos niños están desamparados debido a que a la madre la habian golpeado en ocasión de un robo, lastimándole una pierna que le provocó una trombosis. Tampoco recibió los cuidados médicos por lo que hoy está internada en estado de coma y le tuvieron que amputar la pierna (...) el pronóstico es muy reservado (a punto de morirse). Al comprobar el estado de abandono y el riesgo en el que están inmersos los chicos, el ga- 
binete llama al equipo zonal de la municipalidad con abogada, psicólogo $y$ asistente social.

(...) nos indicó que se busque a los hermanitos y algún adulto (...) a lo que se presentó una prima del padre (que en este momento está preso). (...) se termina con la decisión del equipo zonal de que los niños, (...) mañana los judicializan. La abuela manifestó que no puede hacerse cargo de los chicos. Hace alrededor de 20 días se le murió otra hija. Amén del paro de auxiliares, de que varios de los chicos del turno vinieron sin comer y sólo pudimos darle una medialuna... amén de todo esto, estuvimos trabajando y poniendo el maldito hombro como todos los días. No te escribo más nada. Ya es suficiente" (Coproductora trabajadora de educación, 2009).

"El triálogo es esa nueva forma de establecer contacto con la realidad. Primero en el grupo-equipo, las subjetividades son afectadas (...) transformadas en subjetividades con otra percepción de lo que nos rodea. Nada parece obvio, natural, general o complejo. La única intuición válida es que hay un fenómeno, discurso, politica, cultura, conductas que hay que descifrar que se puede lograr con un trabajo en equipo a través del tiempo" (Coproductor, enfermero en salud mental, 2009).

En síntesis, el esfuerzo teórico comprometido no puede eludir: a. la existencia de sujetos colectivos como actores productores de conocimiento; b. su posibilidad metodológica, empírica y ética; c. el derecho universal que les concierne, el derecho de resistencia y de identidad emancipadora al interior mismo de la producción de conocimiento social.

\section{Bibliografía}

Bhabha, H. (1993). The location of culture, Edit. Routledge, Londres.

Bialakowsky, A.; Patrouilleau, M.; Lusnich C. (2009). “Rationalités universitaires et processus de travail en Amérique Latine pendant l'intervention néolibéral. Alternatives depuis la coproduction de la recherche", Revue du Mauss, Vol.33, París, Francia, p.185202, www.journaldumauss.net.

Bialakowsky, A.; Costa, M.I.; Crudi, R.; Franco, D.; Lusnich, C.; Mota Díaz, L.; Sayago, D. (2008). Rupturas y aperturas de los sujetos colec- 
tivos en praxis de co-investigación, http// www.unne.edu.a r/prealasforo1.htm 1

Bialokowsky, A.; Costa, M. I.; Patrouilleau, M. M.; Martínez Schnaider, R. y López, A. (2007). "Capitalismo y método. Alternativas de la coproducción investigativa", en Revista Sociedad, No 26, Facultad de Ciencias Sociales, UBA, 99-124, Buenos Aires.

Bialakowsky, A.; Costa, M. I.; Patrouilleau, M.; Martínez Schneider, R. y López, A. (2006). “Capitalismo y Método. Alternativas de la coproducción investigativa", en Laboratorio/n line, Año 7, No 19, Instituto de Investigaciones Gino Germani, Facultad de Ciencias Sociales, UBA, Otoño-Invierno, Buenos Aires.

Beck, U. (1999). Un nuevo mundo feliz, Paidós, (2000), España.

Bourdieu, P. (1993). La miseria del mundo, Fondo de Cultura Económica, Buenos Aires.

Candia, J. M. (2006). “De vuelta al trabajo. El movimiento de las empresas recuperadas en Argentina", en Revista. Trayectorias, Año VIII N ${ }^{\circ}$ $22,2006,34-44$.

Dejours, C. (2006). La banalización de la injusticia social, Editorial Topia, Buenos Aires.

Dejours, C.; Dessors, D. y Molinier, P. (1998). "Para comprender la resistencia al cambio", en Organización del trabajo y salud. De la psicopatología a la psicodinámica del trabajo, Asociación Trabajo y Sociedad PIETTE, Lvmen Humanitas, Buenos Aires.

De Sousa Santos, B. (2001). "Los nuevos movimiento sociales", en Revista OSAL, Septiembre de 2001, Argentina.

Dos Santos, T. (1998). "La teoría de la dependencia, un balance histórico y teórico", en Los retos de la globalización. Ensayo en homenaje a Theotonio Dos Santos. Francisco López Segrera (ed.). UNESCO, Caracas, Venezuela.

Fals Borda, O. (1987). Ciencia propia y colonialismo intelectual. Los nuevos rumbos, Carlos Valencia Editores, Bogotá.

Foucault, M. (1978). La verdad y las formas jurídicas, Gedisa, México.

García Liniera, A. (2001). "La estructura de los movimientos sociales en Bolivia", en Revista OSAL, septiembre de 2001, Argentina.

Giroux, H. (2003). Pedagogía y política de la esperanza. Teoría, cultura y enseñan$z a$, Amorrortu Ed., Buenos Aires.

Gramsci, A. (2000). Cuadernos de la cárcel, 6 Vols., Ed. ERA, México, Coedición con UAP. 
Lévinas, E. (1997). Totalidad e Infinito. Ensayo sobre la exterioridad, Ed. Sígueme, Madrid.

Marcuse, H. (1968). El hombre unidimensional, Seix Barral, Barcelona.

Marx, K. (1867). “Cooperación”, Capítulo XI en El capital. Crítica de la Economía Política, Fondo de Cultura Económica (1973), México D.F.

Morin, E. (1984). Ciencia con Consciencia, Anthropos, Barcelona.

Osorio, J. (2004). “Critica de la ciencia vulgar. Sobre epistemología y método en Marx", en Revista Herramienta, N²6, Julio, Buenos Aires.

Osorio, J. (2006). “Biopoder y biocapital. El trabajador como moderno homo sacer", en Revista Nueva Época, año 19, septiembre, 77-98.

Polanyi, K. (2001). La gran transformación, Fondo de Cultura Económica, México.

Portantiero, J. C. (1991). "Gramsci en clave latinoamericana", en Revista Nueva Sociedad N 115 Septiembre/Octubre, 152-157, Buenos Aires.

Quijano, A. (2000). Colonialidad del poder y clasificación social, en JWSR, Journal of World Systems Research Vol. VI No 2.

Retamozo, M. (2006). “Esbozos para una epistemología de los sujetos y movimientos sociales, en Cinta de Moebio, Revista de Epistemología en Ciencias Sociales, N 26.

Rebón, J. y Salgado R. (2007). “Transformaciones emergentes del proceso de recuperación de empresas por sus trabajadores", Labouragain, International Institute of Social History, http:/ / www.iisg.nl/labouragain/argentineantakeovers.php.

Salgado, R. (2010). “Empresas recuperadas por sus trabajadores: sociogénesis y desarrollo del proceso en la Ciudad de Buenos Aires", Documentos de Jóvenes Investigadores, Instituto de Investigaciones Gino Germani, No 24, Facultad de Ciencias Sociales, UBA, Buenos Aires.

Slaughter, J. (1998). "La producción depurada y los buenos empleos", en Reestructuración, integración y mercado laboral, OIT, Chile.

Sotolongo Codina, P. L. y Delgado Díaz, C. J. (2006). La revolución contemporánea del saber y la complejidad social. Hacia unas ciencias sociales de nuevo tipo, CLACSO, Buenos Aires.

Vasilachis de Gialdino, I. (2001). Trabajo e identidad, en $5^{\circ}$ Congreso Nacional de Estudios del Trabajo, ASET, Buenos Aires. 